\title{
ELECTROCHEMICAL PERFORMANCES AND CORROSION INHIBITION OF AA6061 IN TROPICAL SEAWATER
}

\author{
R. Rosliza* \\ Terengganu Advanced Technical Institute (TATI), Teluk Kalong, \\ 24000 Kemaman, Terengganu, Malaysia \\ H.B. Senin \\ Department of Physical Sciences, Faculty of Science and Technology
}

\begin{abstract}
W.B. Wan Nik
Department of Maritime Technology, Faculty of Maritime Studies and Marine Science, University Malaysia Terengganu, 21030 Kuala Terengganu, Terengganu, Malaysia
\end{abstract}

Received 07 June 2007

\begin{abstract}
The corrosion performances of AA6061 aluminum alloy in tropical seawater was investigated using potentiodynamic polarization, electrochemical impedance spectroscopy (EIS) and their morphology was characterized by the scanning electron microscopy (SEM). The results showed that the presence of sodium benzoate as an inhibitor significantly decrease the corrosion current densities $\left(i_{\text {corr }}\right)$, corrosion rates and double layer capacitance $\left(C_{\mathrm{dl}}\right)$, whilst increasing the polarization resistance $\left(R_{\mathrm{p}}\right)$. The scanning electron microscopy (SEM) images indicated that the mechanism of charge transfer and the formation of thin film have been taken place on the specimens.
\end{abstract}

Keywords: Aluminum alloy; Corrosion inhibition; Seawater; EIS; SEM

\section{INTRODUCTION}

Aluminum is an important subject of research because it is abundant in nature, easy to handle and represents an important category of materials due to their high technological value and wide range of industrial applications, especially in aerospace and household industries. In addition, aluminum is justified by low price, high electrical capacity and high energy density [1]. The most important feature of aluminum is its corrosion resistance due to the present of a thin, adherent and protective surface oxide film. Aluminum and its alloy, however, are reactive materials and are prone to corrosion [2].

\footnotetext{
* Corresponding author e-mail: rosliza@ tati.edu.my
} 
The corrosion process in deep seawaters occurs under very specific conditions and is characterized mainly by low temperature, high chloride contents, low oxygen content, the presence of $\mathrm{CO}_{2}$ and $\mathrm{H}_{2} \mathrm{~S}$, microorganisms and high contents of dissolved salts [3]. Seawater systems are used by many industries such as shipping, offshore oil and gas production, power plants and coastal industrial plants. The main use of seawater is for cooling purposes but it is also used for fire fighting, oil field water injection and for desalination plants.

Aluminum alloy is commonly used in marine applications as well. It has the additional advantage of superior resistance to corrosion, since it corrodes over 100 times more slowly than conventional structural carbon steel used to build ships. As reported by [4] in his study on feasibility of replacing structural steel with aluminum alloys in the shipbuilding industry, the materials for body panels of the automobile and the hydrogen gas vessels with high temperature applications $[5,6]$.

The use of inhibitors is one of the most practical methods available for protection against corrosion. Benzoate compounds offer interesting possibilities for corrosion inhibition and are of particular interest because of their safe use and high solubility in water [7]. In the present paper, we report the performances of the potentiodynamic polarization and impedance measurements in order to investigate the corrosion characteristics of aluminum alloys in tropical seawater.

\section{MATERIAL AND METHODS}

\subsection{Samples preparation}

The material employed for this study was AA6061. The test solution used for the investigation was seawater collected from Pantai Teluk Kalong, Kemaman, Terengganu and the inhibitor used was sodium benzoate, $\mathrm{NaBz}\left(1 \mathrm{~g} / \mathrm{dm}^{3}\right.$ concentration). Specimens were cut into $25 \times 25 \times 3 \mathrm{~mm}$ coupons for immersion tests. Before exposure, the samples were mechanically polished using 400, 500 and 600 emery papers and lubricated using distilled water. The polished samples were cleaned with acetone, washed using distilled water, dried in air and stored over a desiccant.

\subsection{Immersion and electrochemical tests}

The samples were immersed in seawater with air circulation and static conditions with and without inhibitor for 180 days. All electrochemical measurements were accomplished with Autolab Frequency Response Analyzer (FRA) coupled to an Autolab potentiostat connected to a computer. The cell used is a conventional three electrodes with a platinum wire counter electrode (CE) and a saturated calomel electrode (SCE) as reference to which all potentials are referred. The working electrode (WE) was in the form of a square cut so that the flat surface was the only surface in the electrode.

The potentiodynamic current-potential curves were recorded by changing the electrode potential automatically from $-100 \mathrm{mV}$ to $+100 \mathrm{mV}$ with the scanning rate of $10 \mathrm{mVs}^{-1}$. Corrosion current densities $\left(i_{\text {corr }}\right)$ and corrosion potential $\left(E_{\text {corr }}\right)$ were evaluated from the intersection of the linear anodic and cathodic branches of the PC as Tafel plots [8]. Tafel plot described the dependence of the current density, $j$, on the overpotential, $\eta$, over the whole range of overpotentials, taking into account mass transport limitation and solution resistance. Impedance measurements have been conducted over a frequency range of $10^{4} \mathrm{~Hz}$ down to $10^{-1} \mathrm{~Hz}$. The scanning rate was 10 $\mathrm{mV} / \mathrm{min}$. Samples were tested at different periods of immersion. Data were presented as Nyquist plots. The results were analyzed using the fit program FRA. 


\section{RESULTS AND DISCUSSION}

\subsection{Potentiodynamic polarization studies}

The changes observed in the polarization curves after addition of the inhibitor are usually used as criteria to classify inhibitors as cathodic, anodic or mixed [9]. Fig. 1 represents the potentiodynamic polarization curves of AA6061 in tropical seawater in the absence and the presence of $\mathrm{NaBz}$ with static and air circulation condition. From the figure, it can be seen that the anodic and cathodic current densities obtained in the presence of inhibitor are lower than as compared to that of in the absence of inhibitor for both of seawater with static and air circulation condition. The corrosion potential $\left(E_{\text {corr }}\right)$ values in the presence of inhibitor are shifted to negative direction and leftward displacement in the cathodic branch of the curves. According to $[9,10,11]$, these are the typical features of cathodic inhibitors, this being in agreement with the results obtained for other aluminum alloys.

Table 1: Electrochemical parameters: corrosion potential $\left(E_{c o r r}\right)$, corrosion current density $\left(i_{\text {corr }}\right)$, and Tafel slopes $\left(b_{a}\right.$ and $\left.b_{c}\right)$ of AA6061 in seawater at room temperature.

\begin{tabular}{|c|c|c|c|c|c|c|}
\hline \multirow{2}{*}{ Condition } & \multirow{2}{*}{$\mathrm{NaBz}$} & \multirow{2}{*}{ Days } & \multicolumn{4}{|c|}{ Potentiodynamic polarization } \\
\hline & & & $E_{\text {corr }}(\mathrm{mV})$ & $i_{\text {corr }}\left(\mu \mathrm{Acm}^{-2}\right)$ & $b_{\mathrm{a}}\left(\mathrm{mVdec}{ }^{-1}\right)$ & $b_{\mathrm{c}}\left(\mathrm{mVdec} \mathrm{d}^{-1}\right)$ \\
\hline \multirow[t]{12}{*}{ Static } & Absense & 30 & -658 & 0.55 & 36 & 494 \\
\hline & & 60 & -658 & 0.91 & 35 & 124 \\
\hline & & 90 & -659 & 1.53 & 43 & 680 \\
\hline & & 120 & -659 & 2.47 & 52 & 72 \\
\hline & & 150 & -664 & 3.00 & 22 & 213 \\
\hline & & 180 & -668 & 3.62 & 42 & 74 \\
\hline & Presence & 30 & -690 & 0.32 & 107 & 118 \\
\hline & & 60 & -685 & 0.50 & 36 & 407 \\
\hline & & 90 & -684 & 0.81 & 35 & 124 \\
\hline & & 120 & -687 & 0.91 & 50 & 136 \\
\hline & & 150 & -688 & 1.05 & 37 & 189 \\
\hline & & 180 & -684 & 1.18 & 43 & 680 \\
\hline \multirow[t]{12}{*}{ Circulation } & Absense & 30 & -728 & 2.75 & 39 & 279 \\
\hline & & 60 & -724 & 3.77 & 32 & 1658 \\
\hline & & 90 & -719 & 4.88 & 65 & 354 \\
\hline & & 120 & -718 & 7.66 & 52 & 109 \\
\hline & & 150 & -720 & 11.76 & 34 & 205 \\
\hline & & 180 & -728 & 12.90 & 33 & 140 \\
\hline & Presence & 30 & -886 & 0.60 & 35 & 124 \\
\hline & & 60 & -869 & 1.33 & 35 & 171 \\
\hline & & 90 & -863 & 2.41 & 44 & 85 \\
\hline & & 120 & -860 & 3.60 & 43 & 74 \\
\hline & & 150 & -871 & 5.53 & 50 & 157 \\
\hline & & 180 & -880 & 6.07 & 48 & 162 \\
\hline
\end{tabular}


The values for the corrosion potentials and corrosion current densities were estimated from the intersection of the anodic and cathodic Tafel lines. The corresponding corrosion potentials $\left(E_{\text {corr }}\right)$, corrosion current density $\left(i_{\text {corr }}\right)$, anodic Tafel slopes $\left(b_{\mathrm{a}}\right)$ and cathodic Tafel slopes $\left(b_{\mathrm{c}}\right)$ are listed in Table 1. From the results obtained, it can be concluded that:

- The values of corrosion current density $\left(i_{\text {corr }}\right)$ for all samples increase with the immersion time. The values recorded are higher in circulating condition as compared to that of in the static condition.

- The change in $E_{\mathrm{corr}}$ is assumed to be related to the growth of a passive layer at the surface of electrode [12].

- The rate of cathodic reaction controls the rate of the corrosion process (as the cathodic overpotential is much greater than that of the anodic one).

- The corrosion current decreases completely after the sodium benzoate is added in both conditions. It is clear that the presence of inhibitor caused markedly decrease in the corrosion rate.

\subsection{Electrochemical impedance spectroscopy}

By analyzing the shape of the obtained Nyquist plots (Fig. 2), it can be concluded that the curves approximated by a single capacitive semicircles, showing that the corrosion process was mainly charge-transfer controlled in electrochemical reactions [13]. The general shape of the curves is very similar for all the samples and this is maintained throughout the whole test period, indicating that almost no change in the corrosion mechanism occurred either due to the immersion time or to the inhibitor addition [14].

After 180 days of immersion time, the values of polarization or charge transfer resistance, $R_{\mathrm{ct}}$ for AA6061 increased for the likely formation (or thickening) of a corrosion product layer on the electrode. The $R_{\mathrm{ct}}$ values were higher for AA6061 after addition of inhibitor at all the immersion time, indicating that the $\mathrm{NaBz}$ is inhibiting the corrosion rate. It can be concluded that $\mathrm{NaBz}$ is an effective inhibitor for the aluminum alloy.

Table 2: Ret and Cdl of AA6061 in seawater obtained using impedance method.

\begin{tabular}{ccccccc}
\hline \multirow{2}{*}{ Days } & \multirow{2}{*}{$\mathrm{NaBz}$} & \multicolumn{2}{c}{ Static } & & \multicolumn{2}{c}{ Air circulation } \\
\cline { 3 - 4 } \cline { 5 - 6 } \cline { 5 - 6 } & & $R_{\mathrm{ct}}(\mathrm{k} \Omega)$ & $C_{\mathrm{dl}}(\mu F)$ & & $R_{\mathrm{ct}}(\mathrm{k} \Omega)$ & $C_{\mathrm{dl}}(\mu F)$ \\
\hline 30 & Absence & 47.00 & 4.43 & & 16.10 & 8.99 \\
60 & & 37.00 & 6.66 & & 12.30 & 9.54 \\
90 & & 29.00 & 7.86 & & 6.73 & 14.11 \\
120 & & 16.80 & 10.21 & & 4.44 & 15.87 \\
150 & & 8.20 & 13.87 & & 3.17 & 18.90 \\
180 & & 4.10 & 16.16 & & 1.07 & 35.77 \\
& & & & & 76.70 & 3.44 \\
30 & \multirow{2}{*}{ Presence } & 83.00 & 1.77 & & 36.00 & 5.55 \\
60 & & 67.30 & 2.03 & & 13.23 & 6.09 \\
90 & & 54.60 & 2.34 & & & \\
120 & & 43.80 & 2.75 & & 9.67 & 8.88 \\
150 & & 25.00 & 4.09 & & 7.12 & 9.55 \\
180 & & 14.70 & 5.03 & & 2.46 & 13.00 \\
\hline
\end{tabular}




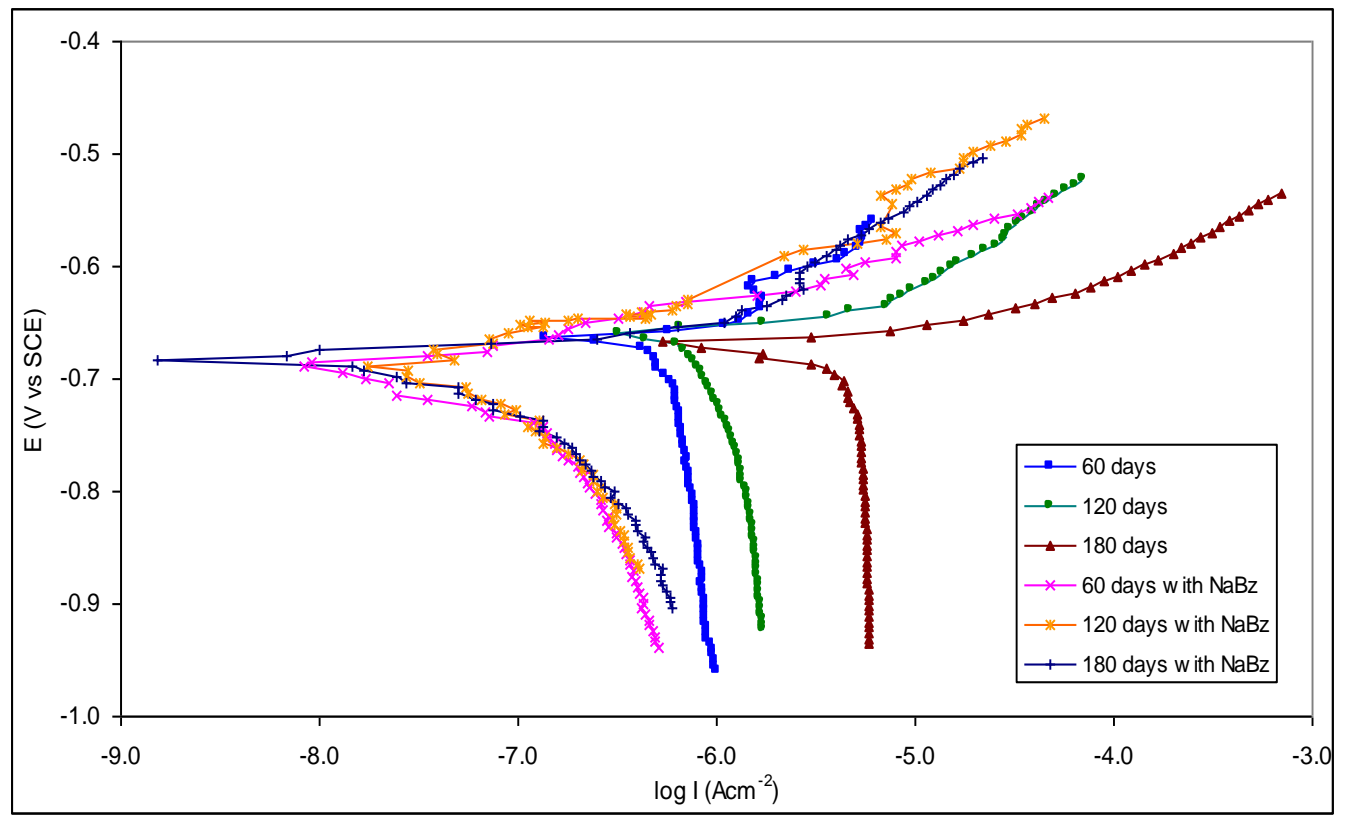

a

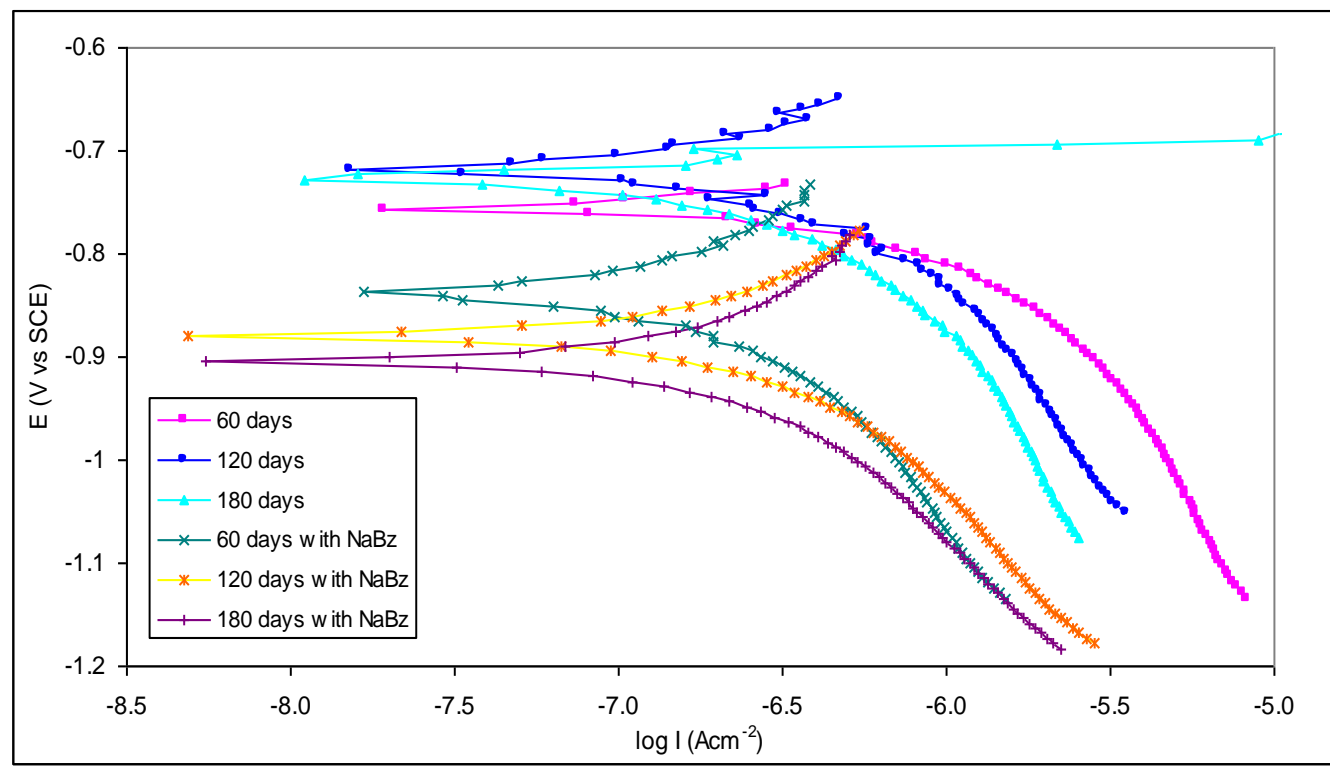

b

Fig. 1: Potentiodynamic polarization curves for AA6061 in seawater with (a) static and (b) air circulation conditions.

The results from Table 2 show $R_{\mathrm{ct}}$ values to decrease with increasing immersion time. There are increasing $R_{\mathrm{ct}}$ values with addition inhibitor as compared to that of without inhibitor. It should be noted that whilst $R_{\mathrm{ct}}$ values increase with addition of inhibitor, the capacitance, $C_{\mathrm{dl}}$ values decrease indicating the formation of a surface film. Effective corrosion resistance is associated 
with high $R_{\mathrm{ct}}$ and low $C_{\mathrm{dl}}$ values [15]. Increase in $R_{\mathrm{ct}}$ values and decrease in $C_{\mathrm{dl}}$ values by NaBz is related to the increased degree of protection of aluminum alloy in seawater. The capacitance decrease as the $\mathrm{NaBz}$ coverage increases since the capacitance is inversely proportional to the distance between the charges.

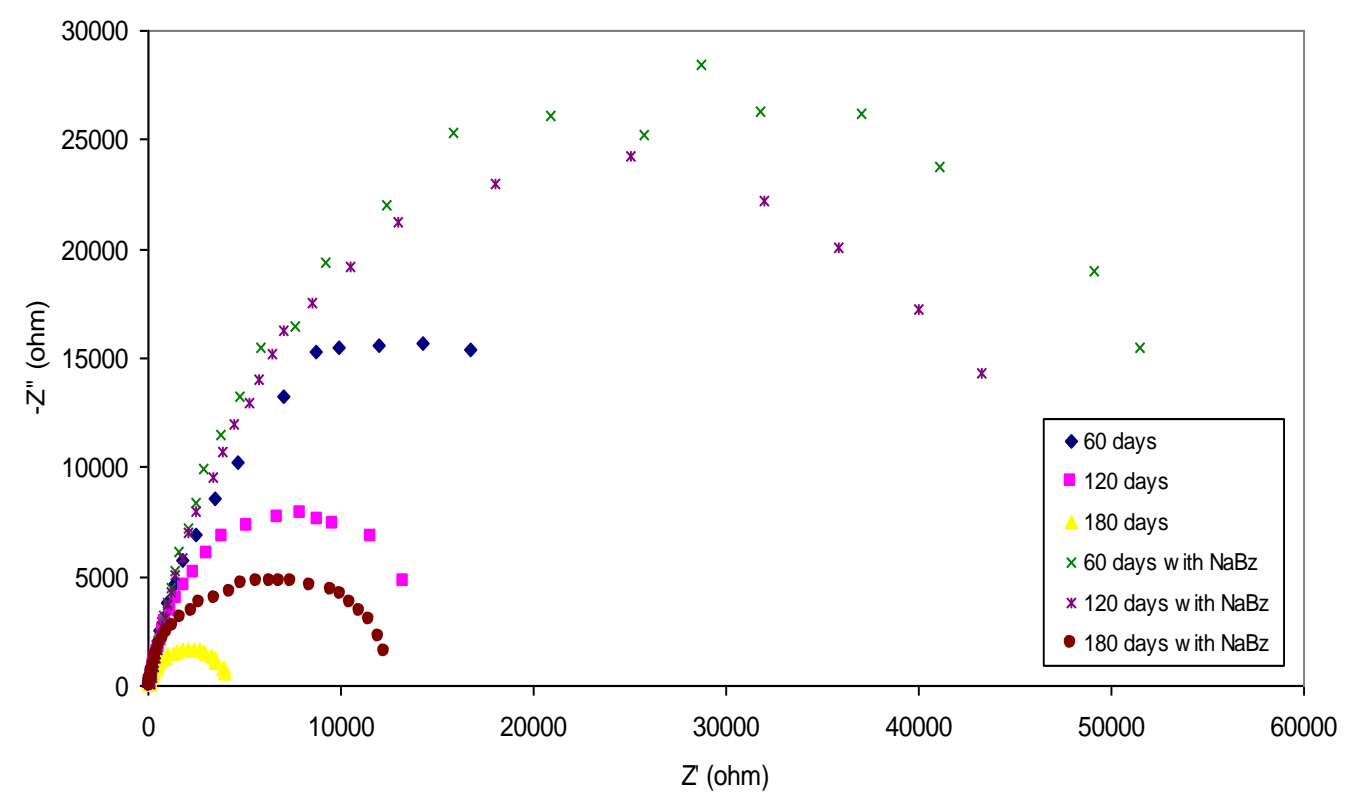

$\mathbf{a}$

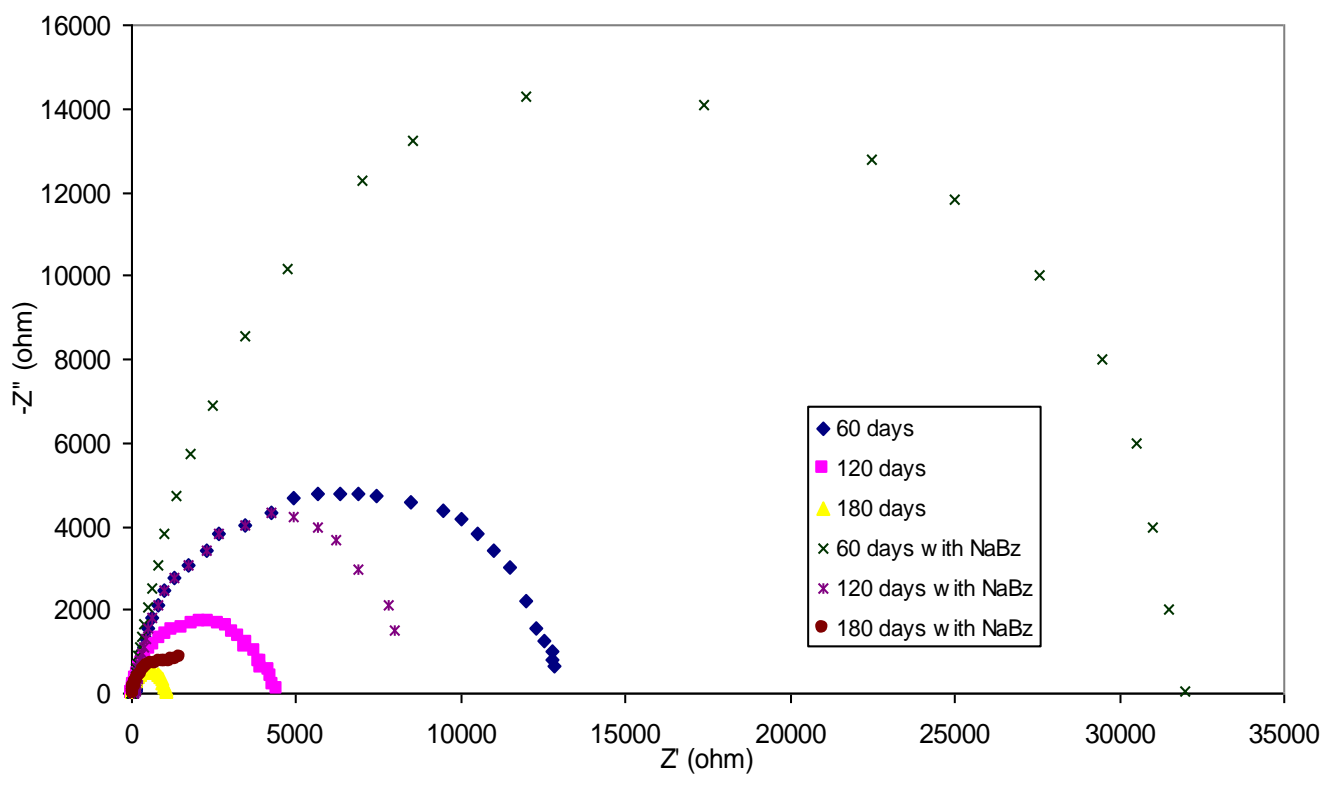

b

Fig. 2: Nyquist plot for AA6061 in (a) static and (b) air circulation conditions in the absence and presence of $\mathrm{NaBz}$. 


\subsection{Scanning electron microscopy}

The SEM micrograph of unexposed of AA6061 to seawater is shown in Fig. 3 (a). It shows that the surface of the metal is absolutely free from any pits and cracks. Polishing scratches are also visible. Fig. 3(b) corresponds to the SEM of specimen surface after 180 days immersed in static seawater. The figures show presence of microorganisms (plankton) on the surface of the specimen which contribute to the corrosion process. Flakes are seen which show corrosion products like metal hydroxides and its oxides. No pits or cracks are observed in the micrographs.

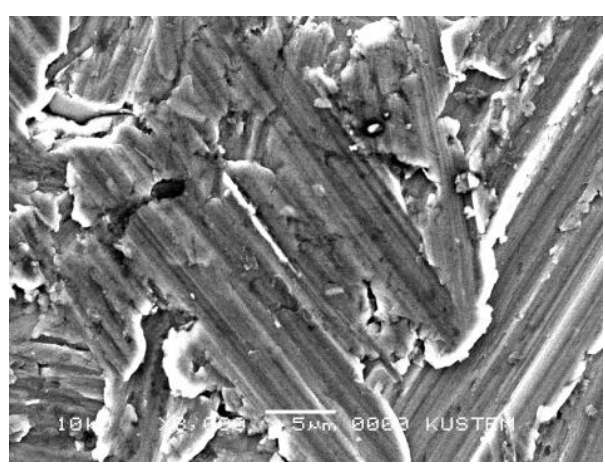

$\mathbf{a}$

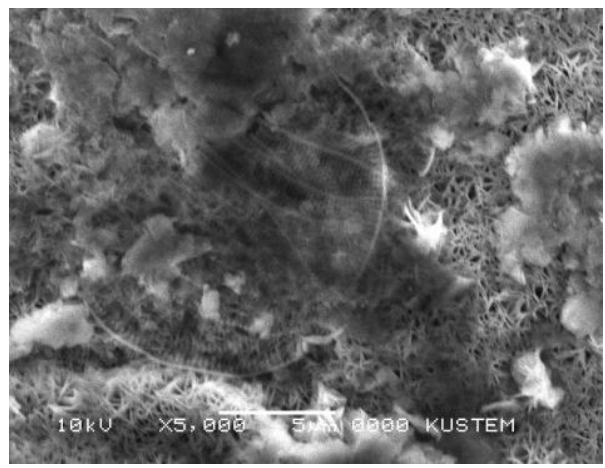

c

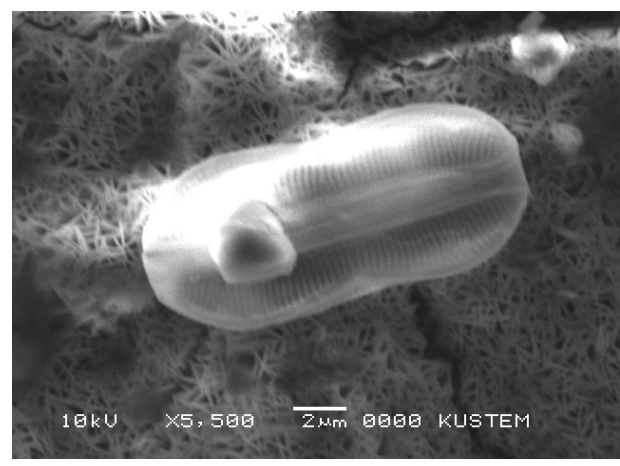

b

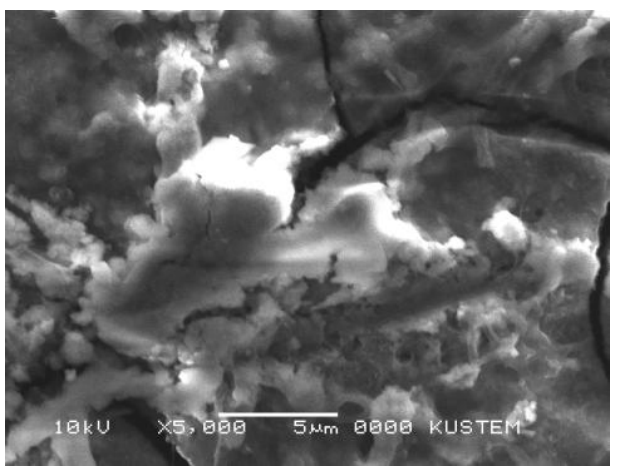

d

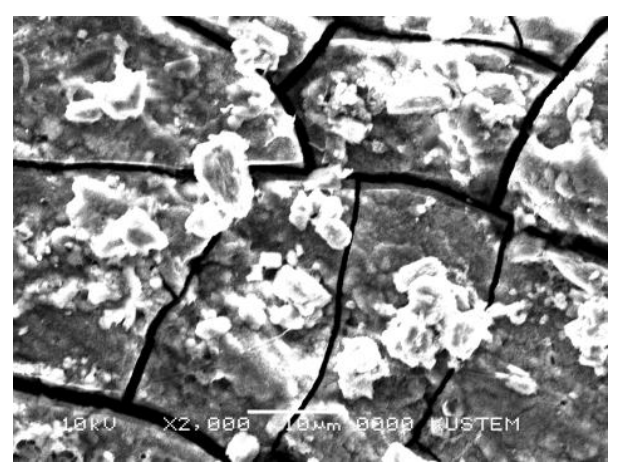

e

Fig. 3: SEM of AA6061 (a) plain surface (b) static without NaBz (c) air circulation without $\mathrm{NaBz}$ (d) static with $\mathrm{NaBz}$ (e) air circulation with $\mathrm{NaBz}$. 
Uniform corrosion can be observed in Fig. 3(c) after 180 days immersed in seawater with air circulation condition. Flakes are seen which show corrosion products like metal hydroxides and its oxides. No pits or cracks are observed in the micrographs. Fig. 3(d) depicts the SEM of specimen surface after 180 days immersed in static seawater with addition of $\mathrm{NaBz}$. It can be seen that the specimen is covered with the inhibitor molecules giving a protection against corrosion, where a thin layer developed on the specimen surface. Fig. 3(e) portrays the SEM of specimen surface after 180 days immersed in circulating seawater with addition of NaBz. A part of the specimen is covered by molecules of inhibitor added in the solution, indicates the developing of thin film. The microorganisms also were covered by the inhibitor molecules as shown in the figure; minimize the activity progress of microorganisms. Hence, reduce the rate of corrosion. The extent of thin film as visible from micrograph is much less compared to that of in static condition with $\mathrm{NaBz}$, giving it fair amount of protection.

\section{CONCLUSIONS}

The corrosion studies of the AA6061 aluminum alloy have been carried out at room temperature using tropical seawater and the results indicate that $\mathrm{NaBz}$ is an effective corrosion inhibitor for AA6061 in seawater.

2. The presence of more dissolved oxygen in air circulation condition contributed to the dissolution of aluminum alloy.

3. The potentiodynamic polarization curves suggested a cathodic character for the inhibition process in seawater.

4. EIS measurements clarified that the corrosion process was mainly charge-transfer controlled and no change in the corrosion mechanism occurred either due to the immersion time or to the inhibitor addition for seawater. It also indicates that the $R_{\mathrm{ct}}$ values increase with addition of inhibitor whilst, the capacitance values decrease indicating the formation of a surface film.

5. Morphology study elucidated that the development of thin film on the specimen immersed in seawater with presence of $\mathrm{NaBz}$ in circulating condition much less compared to that of in static condition, giving it fair amount of protection.

\section{ACKNOWLEDGEMENT}

We would like to acknowledge the financial support from University of Malaysia Terengganu.

\section{REFERENCES}

1. Addel-Gaber, A.M., Abd-El-Nabey, B.A., Sidahmed, I.M., El-Zayady, A.M., and Saadawy, M. (2006), Kinetics and thermodynamics of aluminum dissolution in 1.0 M sulphuric acid containing chloride ions. Mat. Chem. and Phys., vol. 98, pp. 291-297.

2. Badawy, W.A., Al-Kharafi, F.M., and El-Azab, A.S. (1999), Electrochemical behaviour and corrosion inhibition of $\mathrm{Al}, \mathrm{Al}-6061$ and $\mathrm{Al}-\mathrm{Cu}$ in neutral aqueous solutions. Corros. Sci., vol. 41, pp. 709-727.

3. Anselmo, N., May, J.E., Mariano, N.A., Nascente, P.A.P., Kuri, S.E. (2006), Corrosion behavior of supermantensitic stainless steel in aerated and $\mathrm{CO} 2$-saturated synthetic seawater. Mat. Sci. and Eng. A., vol. 428, pp. 73-79.

4. Brown, S. (1999), Feasibility of replacing structural steel with aluminum alloys in the shipbuilding industry, University of Wisconsin, Madison. 
5. Haruna, T., Kouno, T., and Fujimoto, S. (2005), Electrochemical conditions for environment-assisted cracking of 6061 Al alloy. Corros. Sci., vol. 47, pp. 2441-2449.

6. Harley, S.W., Das, S. Miller, J.W. (2000), Aluminum R\&D for automotive uses and the department of energy's role. U.S. Department of Energy, Washington D.C.

7. Blustein, G., Rodriguez, J., Romanogli, R., and Zinola, C.F. (2005), Inhibition of steel corrosion by calcium benzoate adsorption in nitrate solutions: theoretical and experimental approaches. Colloid and Interface Sci., vol. 278, pp. 393-403.

8. Gileadi, E. and Kirowa-Eisner, E. (2005), Some observations concerning the Tafel equation and its relevance to charge transfer in corrosion. Corrosion Science Volume 2005, vol. 47(12), pp. 3068-3085

9. Bethencourt, M., Botana, F.J., Cauqui, M.A., Marcos, M., and Rodriguez, M.A. (1997), Protection against corrosion in marine environments of AA5083 Al-Mg alloy by lanthanide chlorides. Alloys and Compounds, vol. 250, pp. 455-460.

10. Abd El Rahim, S.S., Hassan, H.H., and Amin, M.A. (2002), The corrosion inhibition study of sodium dodecyl sulphonate to aluminum and its alloy in $1.0 \mathrm{M} \mathrm{HCl}$ solution. Mat. Chem. and Phys., vol. 78, pp. 337-348.

11. Aramaki, K. (2001), Effects of organic inhibitors on corrosion of zinc in an aerated $0.5 \mathrm{M}$ $\mathrm{NaCl}$ solution, Corros. Sci., vol 43, pp. 1985-2000.

12. Rosalbino, F., Angelini, E., De Negri, S., Saccone, A., and Delfino, S. (2006), Electrochemical behavior assessment of novel $\mathrm{Mg}$-rich $\mathrm{Mg}$-Al-RE alloys ( $\mathrm{RE}=\mathrm{Ce}, \mathrm{Er}$ ). Intermetallics, vol.14, pp. 1487-1492.

13. Trabanelli, G., Montecelli, C., Grassi, V., and Frignani, A. (2005), Electrochemical study on inhibitors of rebar corrosion in carbonated concrete. Cement and Concrete Research., vol. 35, pp. 1804-1813.

14. Reis, F.M., de Melo, H.G., and Costa, I. (2006), EIS investigation on Al 5052 alloy surface preparation for self-assembling monolayer. Electrochimica Acta., vol. 51, pp. 1780-1788. 